\title{
APLICACIÓN DE LA SEMIÓTICA A LOS PROCESOS DEL DISEÑO
}

\author{
Jacob BAÑUELOS CAPISTRÁN \\ Instituto Tecnológico de Monterrey (México) \\ jcapis@itesm.mx
}

Quien tiene la llave del signo se libera de la prisión de la imagen

Michel Tournier

Resumen: Este artículo ofrece una descripción de los principales componentes de la relación entre la semiótica visual y sus aplicaciones al diseño gráfico. Sobre esta base teórica se propone un modelo de articulación estructural para el análisis y creación de imágenes en diseño gráfico.

Abstract: The present paper gives a description of the principal concepts of the relation between visual semiotics and its applications in the graphic design. With these theoretical basis we propose a structural articulation model of analysis and creation of the image in the graphic design. 
Palabras clave: Semiótica visual. Análisis y creación de imágenes. Procesos de diseño gráfico. Modelo de articulación estructural.

Key words: Visual Semiotics. Analysis and creation of image. Process of graphic design. Structural articulation model.

Son muchas las aportaciones que la teoría del lenguaje y la semiótica han hecho al conjunto de disciplinas que reúne la palabra Diseño. Desde la teoría lingüística elaborada por Ferdinand de Saussure; la pionera definición de signo dada por San Agustín; la teoría de los signos formulada por Charles Sanders Peirce; el estudio de los modos de operación y la función poética de Roman Jakobson en su Arte verbal, signo verbal, tiempo verbal; los estudios semiológicos y estructuralistas sobre poética y retórica, como la aportación de Roland Barthes con su «grado cero de la escritura», la ambigüedad y polisemia del signo visual y su Retórica de la imagen; Jaques Durand con su clasificación de figuras retóricas visuales, en su ensayo «Retórica e imagen publicitaria» y los estudios de Umberto Eco con su Tratado de semiótica general (entre otros); los avances de A. J. Greimás y J. Courtès en Semiótica: diccionario razonado de la lengua y su semiótica planaria; hasta el Grupo $\mu$ con su Retórica general y Tratado del signo visual. El diseño retoma las grandes escuelas del s. Xx como la Vjutemas (Moscú, URSS, 1920) y la Bauhaus (1919-1933, Alemania), así como las Vanguardias Artísticas tanto en principios como en estrategias. Pero el diseño evoluciona y la teoría de los signos le sirve para analizar y crear, para entender el universo de signos, su selección y los resultados de su combinatoria. Veamos una breve descripción de conceptos y relaciones entre la semiótica y su aplicación al diseño gráfico.

\section{SEMIÓTICA}

La semiótica es la ciencia de los signos. La reflexión sobre los signos se confundió durante mucho tiempo con la reflexión sobre el lenguaje. Sin embargo, hay una teoría semiótica implícita en las especulaciones lingüísticas que la Antigüedad nos ha legado: tanto en China como en la India, en Grecia, como en Roma. Los modistas de la Edad Media también formulaban ideas sobre el lenguaje que tienen un alcance semiótico. Pero sólo con Locke surgirá el nombre mismo de «semiótica». En un primer período, la semiótica no se distingue de la teoría general (o de la filosofía) del lenguaje. 
Casi simultáneamente, el filósofo norteamericano Charles Sanders Peirce (1838-1914) y el lingüista suizo Ferdinand de Saussure (1857-1913), anuncian teorías sobre los signos. Saussure declara: «La lengua es un sistema de signos que expresan ideas y, por lo tanto, comparable a la escritura, el alfabeto de los sordomudos, los ritos simbólicos, las formas de cortesía, las señales militares, etc. Es posible concebir así una ciencia que estudie la vida de los signos en el seno de la vida social; tal ciencia formaría parte de la psicología social y, por consiguiente, de la psicología general. La llamaremos semiología (del griego semeion, «signo»). Esta ciencia nos enseñará en qué consisten los signos, qué leyes los rigen. Puesto que todavía no existe, no podemos decir cómo será; pero tiene derecho de existencia y su lugar está determinado de antemano». La aportación de Saussure a la semiología no lingüística se limita prácticamente a esta declaración, que, sin embargo, ha representado un papel muy importante en el desarrollo de la semiótica (Saussure, 1945).

La obra de Charles Sanders Peirce hace posible que la semiótica se convierta en una disciplina, principalmente por sus Collected Papers (Cambridge, 1932). Para este filósofo, la semiótica es un marco de referencia que incluye otros estudios. Apunta: «Nunca me ha sido posible emprender un estudio — sea cual fuere su ámbito: las matemáticas, la moral, la metafísica, la gravitación, la termodinámica, la óptica, la química, la anatomía comparada, la astronomía, los hombres y las mujeres, la psicología, la fonética, la ecnomomía, la historia de las ciencias, el vino, la meteorología- sin concebirlo como un estudio semiótico». Los estudios de Peirce son tan variados como los sistemas aquí enunciados, a los que nosotros incluimos ahora el diseño y sus disciplinas. Peirce no dejó una obra coherente que resumiera su doctrina, lo cual ha convertido su obra en un constructo complejo y cambiante.

Otros autores han contribuido progresivamente al desarrollo de la semiótica, como Ernst Cassier con su obra monumental Filosofía de las formas simbólicas, en la que formula que la función del lenguaje, la articulación de la realidad y su conceptualización, es una comprensión de lo simbólico entendido como todo lo que tiene sentido. Hecho no privativo del lenguaje verbal, sino que lo comparte con sistemas como el mito, la religión, el arte, la ciencia y la historia. El mérito de Cassier es haberse interrogado sobre las leyes específicas que rigen los sistemas simbólicos y sobre su diferencia con las reglas de la lógica: los conceptos múltiples reemplazan a los conceptos generales.

La lógica ha sido una fuente de la semiótica igualmente importante. Charles Morris (lógico y filósofo norteamericano) retoma hacia 1930 los es- 
tudios de Frege, Russel y la construcción de un lenguaje ideal por Carnap. Morris distingue entre las dimensiones semántica, sintáctica y pragmática de un signo: es semántica la relación entre los signos y los designata o denotata; sintáctica, la relación de los signos entre sí; y pragmática, la relación entre los signos y sus usuarios.

Eric Buyssens, en Los lenguajes y el discurso (1943), retoma la escuela funcionalista, para establecer algunas distinciones como sema y acto sémico, semias intrísecas y extrínsecas, semias directas y sustitutivas, que no han sido retomadas por otros autores. Un sistema está organizado por su propia sintaxis, es la premisa funcionalista que está presente en obras de los principales representantes de lo que se llama la «lingüística estructural» (Sapir, Trubetzkoy, Jakobson, Hjelmslev, Benveniste) que toman en cuenta la perspectiva semiológica y procuran precisar cuál es el lugar del lenguaje en el seno de los demás sistemas de signos.

Jan Mukarovsky, uno de los miembros del Círculo Lingüístico de Praga, declara, en su ensayo titulado «El arte como hecho semiológico», que el estudio de las artes debe convertirse en una de las partes de la semiótica e intenta definir la especificidad del signo estético: como un signo autónomo, que adquiere importancia en sí mismo y no como mediador de significación. Pero junto a esta función estética, común a todas las artes, existe otra que poseen todas las artes «con tema» (literatura, pintura, escultura) y que es la función comunicativa: «Toda obra de arte es un signo autónomo. Las obras de arte "con tema" tienen una segunda función semiológica, que es la comunicativa». Charles Morris establece en lo artístico dos clases de signos: los que tienen propiedades comunes con lo denotado y los que no tienen rasgos comunes con lo denotado: signos icónicos y signos no icónicos.

Principalmente en Estados Unidos, Unión Soviética y Francia, los investigadores concentraron los esfuerzos en coordinar las diferentes tradiciones de los estudios semióticos y/o semiológicos, a partir de la Segunda Guerra Mundial. En la URSS, desde los años setenta del s. XX, se desarrolla una intensa actividad semiótica bajo el influjo de la cibernética y la teoría de la información, siendo los trabajos sobre «sistemas secundarios» especialmente originales.

En Francia, impulsaron la semiótica autores como Claude Lévi-Strauss, Roland Barthes y A. Julien Greimas, cuyos trabajos orientaron el estudio de sistemas no lingüísticos (imagen visual, música, gastronomía, diseño, moda, mitos, etc.). En 1969 se publicó la revista Semiótica, órgano de la Asociación Internacional de Semiótica. 


\section{DISEÑO}

El significado del término diseño se ha diversificado ampliamente durante el siglo XX. Podemos hablar de diseño a partir de los siguientes factores, propiciados e impulsados con la Revolución Industrial hacia 1750:

1. INVENCIÓN TECNOLÓGICA.

2. TECNOLOGÍA LABORAL Y MECÁNICA: DIVISIÓN DEL TRABAJO.

3. CONCIENCIA DE EMBELLECER LOS PRODUCTOS INDUSTRIALES.

4. DIVISIÓN TÉCNICA DEL TRABAJO INDUSTRIAL: APARECE EL DISEÑADOR EN EL PROCESO DE PRODUCCIÓN.

5. AUGUE DE LAS ESCUELAS DE DISEÑO.

De tal forma, encontramos el desarrollo de algunas disciplinas especializadas del diseño:

- INDUSTRIAL.

- ARQUITECTURAL.

- URBANO.

- GRÁFICO.

- ICONO-VERBAL.

- AUDIOVISUAL.

- TEXTIL.

- MODA.

A pesar de contar con un desarrollo especializado en áreas del diseño, la palabra diseño se ha convertido en un término complejo, aplicado a cualquier actividad que requiera seleccionar y organizar tanto signos como materiales con una aplicación funcional y práctica, y así encontramos: diseño editorial, diseño de campañas políticas, drogas de diseño, música de diseño, designer food (comida de diseño), diseño genético, etc. Por ello, es interesante esclarecer el significado de la palabra diseño.

Tradicionalmente, diseño ha significado la configuración de los objetos bi o tridimensionales, fabricados en serie por procesos industriales. El diseñador debe abordar un proyecto, conocer bien el problema, su situación, sus ca- 
racterísticas, el material, el soporte, el concepto y la función del objeto o imagen a diseñar. Las premisas del diseño son:

1. FUNCIONALIDAD PRÁCTICA: UTILIDAD.

2. INTENCIONALIDAD-PROPÓSITO: POR EJEMPLO, ERGONOMÍA-MERCADOTECNIA-EMBALAJE, ETC.

3. PLANTEAMIENTO ESTÉTICO (ARMONÍA, «BELLEZA», «GOZO ESTÉTICO»).

Los objetivos que persigue el diseño son:

- DISTINGUIRSE POR SU ORIGINALIDAD.

- MANTENERSE POR SU FUNCIÓN.

- PERPETUARSE MÁs ALLÁ DE SU USO.

El diseñador debe tener en cuenta:

- COMUNICAR Y TRANSMITIR IDENTIDAD.

- SOLUCIONAR PROBLEMAS:

- FUNCIONALES.

- COMUNICATIVOS.

- CULTURALES.

- VINCULACIÓN SOCIAL.

— RESOLVER EL VÍNCULO ENTRE PRODUCTO Y USUARIO.

Yves Zimmermann, en su libro Del diseño, hace una disección de la palabra diseño y sus diversos significados en diferentes idiomas, y establece un paralelismo con la palabra designio, de tal forma que prueba que diseño es designio, propósito, dos veces seña o signo con un propósito o intención (Zimmermann, 1998: 98-121):

- Latín: Diseño y designio: tienen en común seña $=$ signa $=$ signum $=$ señar $=$ señalar $=$ señalizar.

- Francés: Dessin = dibujo. Dessein = designio.

- Italiano: Disegnare, del latin designare $=$ marcar $=$ dibujar $=$ designar $=$ elegir $=$ singularizar $=$ signo de lo singularizado. Designación $=$ asignación $=$ elección de signos $=$ identidad. 
- Inglés: design.

- Alemán: Gestaltung $=$ diseño $=$ configuración. Gestalt $=$ forma. Absicht $=$ designio $=$ sicht $=$ visión $=$ tener-en-vista-un propósito .

- Griego: Di-seño $=\mathrm{Di}=$ dia $=$ dividido $=$ dos veces $=\langle$ dos veces el objeto a través del signo»= signo como re-presentación: «evocación de la ausencia de un objeto o referente». De-signio = «pertenecer a». Di y $\mathrm{De}=$ expresa $\ll$ lo perteneciente a la seña» $=$ lo que posee signo.

Diseñar es llevar el objeto a su signo. Designio es intención de signo. Hay una íntima relación entre diseño y designio, relación que lleva consigo todo diseño por definición: signo con intención.

\section{LO GRÁFICO}

Lo gráfico es un signo, el acto gráfico fundamental, siguiendo a Gibson, es el trazo que deja el hombre como una huella, sobre una superficie como una forma estática, que permanece, para mostrar así el gesto de ese trazo, el movimiento de dicho trazo en una huella (James Gibson, The senses considered as perceptual systems, Boston: Hougton Mifflin. Citado en Zunzunegui, 1992).

Este trazo puede ser a manera de canal (dedo, punzón, palo, etc.) o al dejar un depósito (tiza, carbón, pigmentos, etc.), por lo tanto es táctil y visual. Su esencia consiste en generar un cambio en una superficie, variando su forma de estructurar la luz. En este sentido todo trazo gráfico es una huella visual.

Sin embargo, hoy asistimos a un cambio ontológico en la naturaleza de lo gráfico, si no radicalmente en lo ontológico, sí en su conceptualización, ya que hablamos de lo gráfico digital o de lo infográfico. Y este radical cambio consiste precisamente en que tenemos imágenes sin huella, imágenes no indicales. Por lo que no podemos estar de acuerdo con la afirmación de que «toda imagen es una huella». El «acto gráfico fundamental» tiene hoy su contraparte: «el acto gráfico digital». Hoy en día no toda imagen es una huella, no todo lo gráfico, en sentido figurado, es huella, debido al cambio tecnológico en la producción de imágenes, ahora posibles de manera electro-digital, con todas las implicaciones ontológicas que esto significa, es decir, la ausencia de matriz indical, la ausencia de huella: lo gráfico como signo visual sin huella. 


\section{SEMIÓTICA DEL SIGNO VISUAL}

No todo signo es visual. Por lo tanto, es preciso limitar el estudio del signo en lo relativo al Diseño Gráfico, como disciplina generadora de signos gráficos y, por ende, visuales. Pero antes de abordar los signos visuales, es preciso definir el signo.

Las teorías modernas del signo, procuran abarcar no sólo entidades lingüísticas, sino también signos no verbales. San Agustín escribe una primera definición del signo:

El signo es cualquier cosa que nos haga venir a la mente otra cosa más allá de la impresión que la cosa misma causa a nuestros sentidos (De Doctr. II.I.I. 5).

Esta definición está ya muy cerca de lo que para Charles Sanders Peirce es un signo:

El signo no es un signo si no puede traducirse en otro signo en el cual se desarrolla con mayor plenitud (Abbagnano, 1986).

Peirce va más lejos del planteamiento hecho por Saussure sobre el signo, que se da como resultado de la relación entre el significante (aspecto material del signo) y el significado (concepto).

Para Peirce, como se ha apuntado arriba, un signo sólo significa dentro de un sistema de signos y sólo en virtud de que los demás signos del sistema también significan. A este proceso de signos se le denomina semiosis, y está constituido por la relación de tres elementos: el signo, el objeto y el interpretante. Éstas son las principales relaciones triádicas que establece Peirce. La teoría del signo desarrollada por Peirce es compleja y su explicación desborda la extensión de este somero estudio sobre los signos y su relación con el diseño gráfico.

Así que nos centramos en la tríada de signos que nos sirven para describir las imágenes y las relaciones triádicas de funcionamiento cuya naturaleza es la de los hechos reales:

Un signo visual puede ser denominado:

- Icono: el que está fundado en la similitud entre el representante y lo representado. 
- Índice: el que resulta de la contigüidad física entre el representante y lo representado, es decir, un index, que remite a hechos o cosas reales, singulares, de los que depende su existencia.

- Símbolo: aquel signo cuya existencia se basa en una convención social.

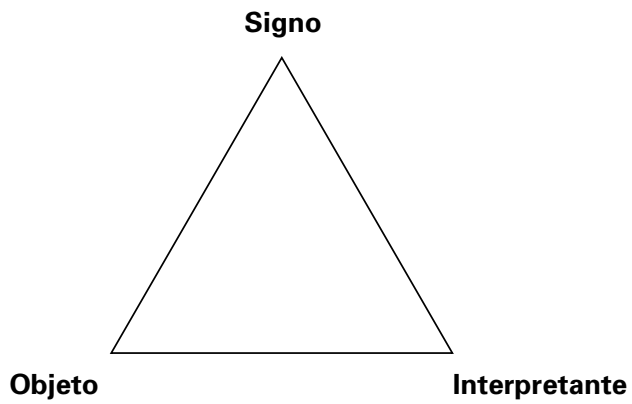

Relación triádica del signo, objeto e interpetante.

En lo tocante al ejercicio analítico y creativo de la semiótica en el proceso del diseño gráfico, diremos que es necesario acotar el campo semiótico a lo visual y lo visual a lo bidimensional, es decir, a textos visuales, no necesariamente icónicos, de carácter planario, para constituir una semiótica planaria.

La aportación de la semiótica planaria distingue una semiótica figurativa y una semiótica plástica. La semiótica figurativa reagrupa los trazos visuales que componen una imagen en formantes figurativos, esto es, en signos-objetos, elementos del plano expresivo, representaciones parciales de los objetos del mundo natural mediante un código de reconocimiento. Esta semiótica figurativa incluye, sin embargo, la posibilidad de distinguir entre significado y significante, es decir, proceder a la articulación del mundo visible o de un universo visible construido por unidades que no coinciden con las del mundo natural.

La semiótica plástica plantea la construcción de la imagen como la construcción del plano de la expresión visual, como resultado de la articulación de diversas categorías: las constitucionales —que permiten la aprehensión de una configuración plástica- como las cromáticas (color, contraste, saturación, luminosidad, etc.); y las no constitucionales — que regulan el lugar de los elementos visuales en el espacio planario de la imagen (orientación: alto/bajo, derecha/izquierda; posición: periférico/central, englobante/englobado)—. 


\section{ANÁLISIS SEMIÓTICO}

El análisis semiótico de los productos visuales del diseño gráfico, permite comprender claramente:

a) Sus fundamentos y elementos constitutivos a partir de signos y de una teoría de los signos.

b) Su proceso constructivo como sistema semiótico de significación y de comunicación.

c) Que son productos de un sistema semiótico de signos indicales, icónicos y simbólicos y figuras de un código gráfico, en comunidades humanas históricas que lo emplean como medio de representación y apropiación de la realidad y la expresión del pensamiento.

d) Las relaciones internas, la interacción semiótica y estética entre los elementos sígnicos que lo componen, a nivel lógico, morfosintáctico y semántico. Es decir, las relaciones de los signos entre sí, las relaciones de los signos con el objeto, dentro y fuera de un sistema.

e) Comprender sus relaciones semánticas con el interpretante, intérprete, espectador, lector: su pragmática. Es decir, las relaciones de los signos con quien utiliza y percibe los signos. Sus interacciones sociales, su semiosis social, con el contexto y el sujeto, a nivel de la percepción (modelos de percepción, cognoscitivo y paradigmático) (Peirce, 1932).

\section{POÉTICA Y RETÓRICA DEL DISEÑO GRÁFICO}

Al análisis semiótico se suman los desarrollos de estudios hechos sobre poética y retórica visual, que enriquecen dicho análisis. Relevantes son los estudios de Roman Jakobson, Umberto Eco, Grupo $\mu$, Jaques Durand, A. J. Greimas, J. Courtés, John Lyons, Antonio García Berrio, quienes reflexionan desde una posición estructuralista, a quienes se suman modelos de articulación de unidades estructurales como el de Sephen Palmer, que veremos más adelante. Tienen sin duda un antecedente clásico en los estudios tradicionales de Aristóteles (384-322 a.C.) en su Arte Poética, y en Horacio con su Epístola a los Pisones (o Poética, 13 a.C.).

La retórica visual o no visual, se funda en el arte del manejo de las figuras establecidas por convención histórica y cultural, con el fin principal de generar un discurso persuasivo. La poética visual (o no visual) es el arte del desvío de las normas, el desvío de los signos, ya que, según la definición artistotélica, la 
poesía no representa las cosas realmente sucedidas, sino las cosas posibles, es decir, la expresión de lo posible (imaginario o no) es la expresión poética.

Los productos del diseño gráfico transitan entre un discurso poético y retórico de la imagen, como reunión diversa de signos visuales, como resultado de su fusión e interacción, ya que el signo visual puede convertirse en otro(s) signo(s) en la reconstrucción que elabora el espectador.

Roman Jakobson (lingüista ruso), publica, en 1960, su famoso ensayo «Lingüística y poética», dentro del libro Ensayos de Lingüística General, en donde expone la teoría de la gramática de la poesía y la función poética, considerando el dinamismo del arte verbal, pero igualmente el de los sistemas semióticos de comunicación en general (como la imagen fija, la gráfica, el cine, etc.) y considerando igualmente al tiempo como sistema semiótico que produce impulso y cambio. Jakobson funda una teoría general de la poética, y se hace una pregunta básica:

¿Cuál es el criterio lingüístico empírico de la función poética? En general, ¿cuál es el rasgo indispensable inherente en cualquier fragmento poético?

Y responde:

Para contestar a esta pregunta, tenemos que invocar los dos modos básicos de conformación en la conducta verbal, la selección y la combinación.

La selección se produce sobre la base de la equivalencia, la semejanza y desemejanza, la sinonimia y la antonimia, mientras que la combinación, la construcción de la secuencia, se basa en la contigüidad. La función poética proyecta el principio de la equivalencia del eje de selección al eje de combinación. La equivalencia pasa a ser un recurso constituido de la secuencia (Jakobson, 1981):

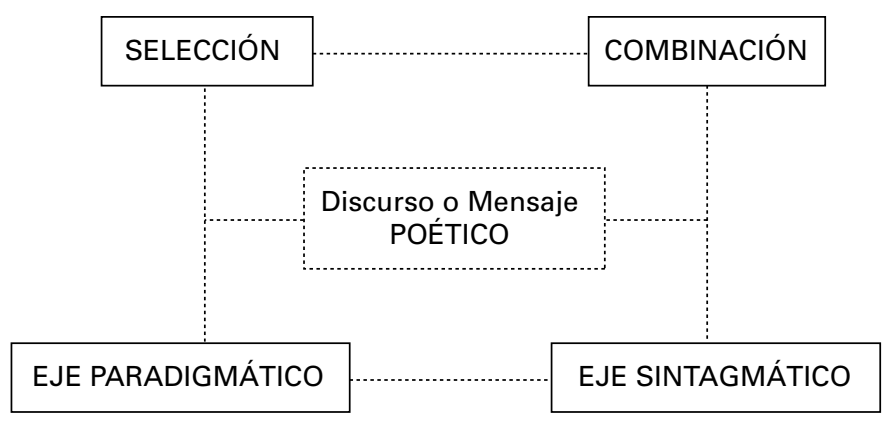

Formulación de las operaciones poéticas de Jacobson. 
Esta formulación vale para cualquier tipo de expresión, y para el carácter intertextual de los productos del diseño gráfico, ya que los problemas de la construcción de un discurso poético o retórico rebasan los límites de un solo sistema de signos (el linguístico) o de un solo arte, y pertenece a la teoría general de los signos, esto es, a la semiótica general. Las atribuciones del discurso poético son su esencia enteramente simbólica, múltiple, ambigua y polisémica (como vemos en el ejemplo del rostro más adelante analizado).

La poeticidad, como afirma Jakobson, no consiste en añadir una ornamentación retórica al discurso, sino en una revalorización total del discurso y de cualesquiera de sus componentes.

Los estudios del Grupo $\mu$ (Tratado del signo visual, 1992) merecen atención, ya que intentan una sistematización de los signos visuales (plásticosicónicos-iconoplásticos), una clarificación de conceptos como grado cero, norma, desvío, así como un análisis de las cuatro operaciones básicas de la retórica icónica (adjunción, supresión, adjunción-supresión y permutación) —operaciones básicas en la construcción de figuras retóricas visuales- y el ethos de las figuras plásticas-icónicas, desde bases psicofisiológicas de la percepción visual, con un enfoque semiótico estructuralista (Grupo $\mu$, 1992).

Los elementos constitutivos de las figuras retóricas y poéticas, con las que juega el diseño gráfico, son precisamente aquellos elementos visuales como el punto, la línea, el fondo, la forma, la textura, el color, contorno, dirección, tono, luminosidad, saturación, brillo, contraste, tono, dimensión, movimiento, y todos los signos visuales; así como las técnicas de composición como el equilibrio, la armonía, encuadre, plano, ángulo, punto de vista, simetría, etc. que son algunas por sí mismas ya figuras retóricas, y de cuya articulación y desvío dependerá el resultado de la imagen más la dominante del discurso estético que se sume en la elaboración final.

Para el Grupo $\mu$, las operaciones retóricas solamente son aquéllas que persiguen efectos poéticos y tienden a confundir la poética con la retórica:

Denominaremos solamente retóricos los desvíos cuya finalidad es la de apuntar a efectos "poéticos», respondiendo así a la observación empírica según la cual a todo desvío percibido por un destinatario se le atribuye inmediatamente una significación. Fuera incluso de la naturaleza del desvío, el solo hecho del desvío está cargado de sentido: significa precisamente Retórica, es decir, Literatura, Poesía, Humor, etcétera (Peirce, 1932). 


\section{Cuadro 1}

\begin{tabular}{|c|c|c|c|c|}
\hline \multirow[t]{2}{*}{$\begin{array}{l}\text { Relación } \\
\text { entre } \\
\text { elementos } \\
\text { variantes }\end{array}$} & Adjunción & OPERACIONE & $\underbrace{\text { RETÓRICAS }}_{\substack{\text { Adjunción } \\
\text { Sustitución }}}$ & $\begin{array}{l}\text { Permutación } \\
\text { Intercambio }\end{array}$ \\
\hline & identidad & $\begin{array}{l}\text { similitud } \\
\text { inclusión }\end{array}$ & $\begin{array}{c}\text { diferencia } \\
\text { intersección }\end{array}$ & $\begin{array}{l}\text { oposición } \\
\text { exclusión }\end{array}$ \\
\hline 1. Identidad & $\begin{array}{l}\text { Repetición, insistencia, } \\
\text { aliteración, epistrofe, } \\
\text { anáfora, } \\
\text { apanáfora/epifora, } \\
\text { concatenación, } \\
\text { epanadiplosis, } \\
\text { reduplicación, } \\
\text { geminación, gradación, } \\
\text { simploque, anadiplosis, } \\
\text { epoanalepsis, } \\
\text { «redditio», «repetitio» }\end{array}$ & $\begin{array}{c}\text { Elipsis, silencio, } \\
\text { aposiopesis, } \\
\text { zeugma, } \\
\text { parataxis }\end{array}$ & $\begin{array}{l}\text { Hipérbole, sinonimia } \\
\text { con/sin base } \\
\text { morfológica: } \\
\text { bimembre- } \\
\text { trimembre, } \\
\text { neologismo, } \\
\text { invención ho,onimia, } \\
\text { lítote }\end{array}$ & $\begin{array}{l}\text { Inversión: } \\
\text { lógica, } \\
\text { cronológica } \\
\text { regresión }\end{array}$ \\
\hline $\begin{array}{l}\text { 2. Similitud } \\
\text {-forma } \\
\text {-semántica }\end{array}$ & $\begin{array}{l}\text {-rima, paranomasia, } \\
\text {-comparación, } \\
\text { pleonasmo, expolición }\end{array}$ & Circunloquio & $\begin{array}{l}\text { Metáfora, alusión } \\
\text { alegoría, fábula, } \\
\text { parábola }\end{array}$ & $\begin{array}{c}\text { Endiasis } \\
\text { homología }\end{array}$ \\
\hline 3. Diferencia & $\begin{array}{c}\text { Acumulación, } \\
\text { «epitrocasma», } \\
\text { conjunción, disyunción } \\
\text { o asíndeton, prótesis, } \\
\text { enumeración (caotica y } \\
\text { aglomerada), } \\
\text { distribución, } \\
\text { amplificación }\end{array}$ & $\begin{array}{l}\text { Suspensión, } \\
\text { digresión } \\
\text { antonomasia } \\
\text { particularizante }\end{array}$ & $\begin{array}{c}\text { Crasis, metalepsis, } \\
\text { metonimia: causal, } \\
\text { espacial, espacio- } \\
\text { temporal; silepsis } \\
\text { sinecdoque } \\
\text { particularizante/gener } \\
\text { alizante }\end{array}$ & $\begin{array}{l}\text { Hipérbaton } \\
\text { anástrofe } \\
\text { anagrama }\end{array}$ \\
\hline $\begin{array}{l}\text { 4. Oposición } \\
\text {-toma } \\
\text {-semántica } \\
\text {-lógica }\end{array}$ & $\begin{array}{l}\text { Anacronismo, enganche } \\
\text {-antitesis, simetría }\end{array}$ & $\begin{array}{l}\text {-dubitación } \\
\text {-reticencia, } \\
\text { silencio }\end{array}$ & $\begin{array}{c}\text {-perifrasis, silepsis, } \\
\text { quiasmo } \\
\text {-eufemismo, } \\
\text { oxímoron } \\
\text { antanaclasis, dialogía } \\
\text {-antífrasis }\end{array}$ & $\begin{array}{l}\text { hipálage } \\
\text { anacoluto } \\
\text {-paralelismo } \\
\text { antepódosis }\end{array}$ \\
\hline $\begin{array}{c}\text { 5. Falsas } \\
\text { homologías } \\
\text {-doble } \\
\text { sentido } \\
\text {-paradoja }\end{array}$ & $\begin{array}{c}\text { atanaclase } \\
\text {-dilema, «inventio», } \\
\text { antinomia }\end{array}$ & $\begin{array}{l}\text {-tautología } \\
\text {-preterición }\end{array}$ & $\begin{array}{c}\text {-retruecano } \\
\text {-antifrasis ironía, } \\
\text { paradoja }\end{array}$ & $\begin{array}{c}\text { antimatábola } \\
\text {-antilogía }\end{array}$ \\
\hline
\end{tabular}


Para zanjar la distinción entre poética y retórica visual, citamos una declaración de Umberto Eco, con la que coincidimos:

[...] no se pueden reducir las leyes de la poesía a las leyes de la retórica. Lo que caracteriza a la poesía es asumir los fenómenos retóricos como elocutio $y$ compositio en cuanto organizados y prescritos por un sistema de reglas particulares. Así pues, la modalidad poética no se caracteriza por esos fenómenos retóricos, sino por la decisión de usar esos artificios de determinado modo (...) para caracterizar lo poético en sentido estricto... no valen las categorías retóricas (Grupo $\mu, 1987: 87$ ).

Lo anterior sencillamente contradice la tesis de una panretórica visual, ya que libera a la poética del yugo retórico, devolviéndola a su lugar de origen, como creadora inmanente de un nuevo descubrimiento.

Adjuntamos en la página anteriro el cuadro de clasificación de operaciones y figuras retóricas, elaborado por Jaques Durand, en donde se plasma un intento de sistematizar la construcción de figuras retóricas visuales (Durand, 1972: 88).

\section{ANÁLISIS TEÓRICO Y CREACIÓN}

Modelo del proceso de creación del diseño gráfico: Fotomontaje de un rostro

A continuación se presenta un modelo del proceso de creación de un diseño gráfico, elaborado mediante la estrategia del fotomontaje. Tal modelo está basado en la teoría lingüística de la creación poética y retórica diseñada por Jakobson (arriba estudiada), así como en las relaciones que se establecen entre los signos de una imagen (identidad, similitud, diferencia, oposición) y que se articulan mediante las operaciones de creación retórica (adjunción, supresión, adjunción-supresión y permutación). Aparece igualmente el universo de imágenes o signos visuales, que son piezas paradigmáticas a partir de las cuales se comienza el proceso creativo, el proceso de selección y articulación. Igualmente, este proceso va acompañado de estrategias técnicas, que el creador tendrá que elegir, como son: el collage, emparedados, fotograma, exposiciones múltiples, maqueta y/o escenificación, montaje en ampliadora, tratamiento digital, o bien, combinar estas técnicas. Para dar lugar, así, a una imagen con una gradación que irá de lo retórico a lo poético, dependiendo de la intensidad del desvío dado en la intervención de los signos elegidos. Finalmente, atenderemos a un montaje, que será reproducido y puesto en soporte mediante una matriz analógica o digital, multi-reproductiva y modificable. 


\section{Modelo de articulación de unidades semiótico-estructurales}

El diseño gráfico de un fotomontaje se inscribe dentro de los fenómenos visuales considerados como productores de signos. Lo que posibilita abordar un estudio semiótico, retórico y poético del mismo. En seguida presentamos un esquema que representa un modelo de articulación de unidades semióticoestructurales, elaborado por Stephen Palmer, y que retomamos aquí como modelo de articulación semiótico-pertinente para el análisis del fotomontaje de un rostro.

El modelo presentado por Palmer es útil para emprender un análisis semiótico. Permite traducirlo como modelo de articulación de signos con el fin de representar su relación tanto en el eje paradigmático como en el eje sintagmático.

Palmer intenta sintetizar los enfoques gestaltista (holista) y estructuralista (atomista), bajo la forma de una red jerarquizada de unidades estructurales. Entre ambos enfoques no existe una separación pragmática, los dos explican fenómenos en el reconocimiento visual. «Las figuras globales pueden ser descompuestas en partes; y el conjunto global tiene propiedades que las partes no tienen.»

En cada nivel del esquema de Palmer, de esta red de unidades estructurales, las unidades semióticas están definidas, a la vez, como un conjunto de propiedades globales (gestalt), y como un conjunto organizado de partes como propiedades atómicas (estructural). Pueden existir varios niveles jerarquizados en una representación dada, pero a priori, ninguno es dominante: «las partes poseen el mismo estatuto lógico que el todo» (Grupo $\mu, 1987: 87$ ).

Las unidades del esquema de Palmer son elementos de representación, semas, susceptibles de ser tratados en bloque, incluso si poseen una gran complejidad interna (por ejemplo: ojo, nariz, boca, frente). Dichas unidades son igualmente definidas como unidades de información o chunks (migas), en las que se dan una recodificación, una reagrupación de los signos, a través de procedimientos que pueden variar de cultura a cultura, e incluso de individuo a individuo.

En el esquema de Palmer las unidades estructurales son definidas por las propiedades globales - intrínsecas-y por las propiedades atómicas - extrínsecas - de cada signo, que tienen asignado algún valor.

Las propiedades globales son valores cuantitativos y cualitativos según dimensiones perceptivas, especificadas con relación a un cierto referente. Por 


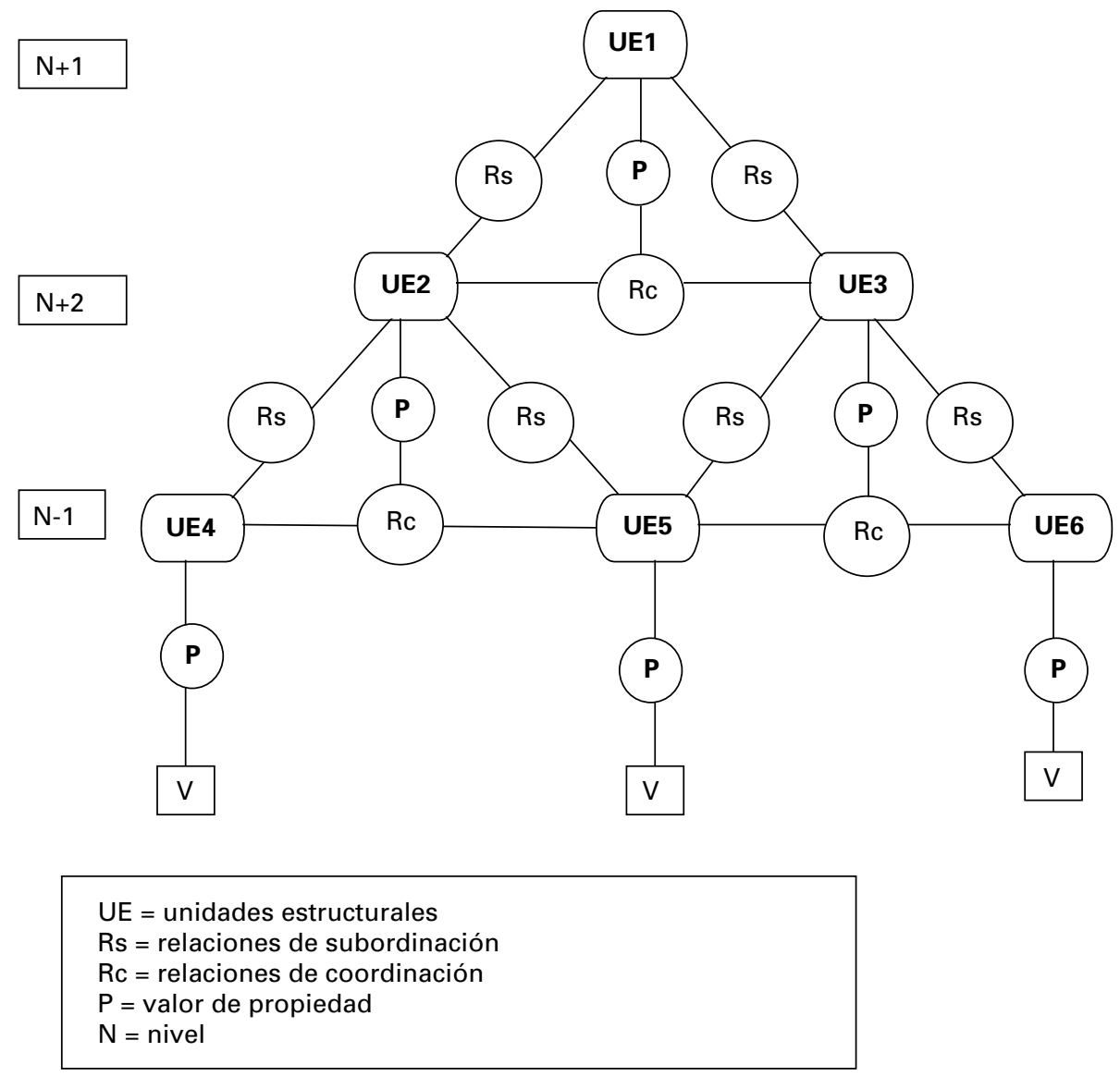

ejemplo, el tamaño de un ojo podría estar determinado por el tamaño de la cabeza. Para nuestro uso, las propiedades globales también pueden referirse a otras propiedades de las formas: color, textura, dimensión, etc. Las propiedades globales son de tipo intrínseco, ya que se corresponden a un modelo-tipo cultural: por ejemplo, el modelo del ojo.

Las propiedades atómicas tienen un estatuto estable y unívoco. Por ejemplo, la coordinación de los dos ojos y su subordinación en la cara son relaciones permanentes que pueden describirse con precisión.

Por el contrario, las propiedades globales - intrínsecas - son propiedades tales como: elongación relativa, anguloso/redondeado, alargado/rechon- 
cho, etc., que toman para tal unidad estructural un valor determinado. Las propiedades globales (intrínsecas) son combinaciones, intregraciones o síntesis de las propiedades de un orden superior.

Se puede afirmar que las propiedades atómicas (extrínsecas) son objetivamente descriptibles, y que las propiedades globales (intrínsecas) son síntesis subjetivas, siempre parciales, movedizas e hipotéticas.

Cada unidad estructural (UE) se define por sus partes subordinadas y por las relaciones entre ellas. Por ejemplo, en el fotomontaje de un rostro, ésta es definida como y por el conjunto de dos ojos, una nariz, una boca, una frente, etc., colocados en una posición respectiva dada y precisa. Las UE hacen intervenir relaciones de subordinación, supraordenación y de coordinación (ver figura Rostro, más abajo).

Un proceso de análisis de las unidades estructurales, conduce a la identificación de tipos paradigmáticos y cognitivos, pertenecientes a los repertorios de signos: en el caso de un fotomontaje de un rostro, cada fragmento fotográfico (la foto de un ojo, una boca, una nariz, etc.) correspondería a cada unidad estructural sémica.

En el examen de un fotomontaje, de un espectáculo artificial o de un evento natural, lo primero que reciben los sentidos es un conjunto de estímulos. En un primer momento del análisis de la imagen hay un rechazo a la integración, sólo funcionan los detectores de formas, texturas y colores. La segregación de las unidades estructurales es posterior, y resulta de la integración de estos rasgos (formas, texturas, colores), en correspondencia con un tipo del repertorio.

Estas integraciones son siempre conjeturales: susceptibles de ser descompuestas por un modelo o esquema más económico y más completo (que rinda cuentas de una mayor cantidad de rasgos). La lectura del campo visual procede de lo global a lo local, ya que primero se perciben las propiedades de conjunto. Estas síntesis pueden desplazarse de nivel a nivel, y no están obligadas a tomar todos los niveles subordinados.

En el caso de la lectura de la propiedad global —si consideramos la boca, la nariz y los ojos - es simultánea: pero se detiene al nivel de la unidad estructural cara o rostro. No se aprehende (o percibe) simultáneamente la estatura de un hombre y el color de sus ojos o los pelos de su nariz. Sin embargo, mediante un fotomontaje, sí que se pueden representar tales cualidades o valores, con unidades estructurales particulares de una unidad estructural superior, con lo que la síntesis sí que puede darse entre niveles supuestamente subordinados. 
Puede haber varias oscilaciones antes de que la integración se equilibre en un modelo de lectura determinado y estable. Únicamente en ese momento los estímulos elementales o rasgos adquieren el estatuto de determinantes, ya que su presencia es la manifestación del tipo paradigmático.

Se puede establecer que únicamente los determinantes son físicos ( «reales»), en la medida que existen en su integración con el sistema nervioso periférico. Por otra parte, las unidades estructurales son conjeturas semióticas, constructos o representaciones conceptuales. Se aclara así, la relación entre lo perceptual y lo conceptual.

Es preciso señalar las relaciones que se establecen entre las unidades estructurales. Diremos que se trata de relaciones dialécticas dadas entre unidad (de nivel superior) y partes de unidad. Cada unidad o parte de unidad sólo tiene valor a causa de su posición en un enunciado visual. Mantiene relaciones de cuatro clases:
a) coordinación
b) subordinación, a una unidad de nivel superior
c) supraordenación, con relación a unidades de nivel inferior
d) preordenación.

Podemos destacar dos tipos de unidades estructurales: las globales o superiores, y las inferiores. Por ejemplo: rostro es una unidad superior en función de los ojos, la nariz, la boca, etc. (unidades de nivel inferior, que la conforman), pero es inferior con relación a una unidad superior como el cuerpo humano.

Las relaciones de coordinación y subordinación dan lugar a las llamadas propiedades atómicas. Las relaciones de supraordenación y preordenación proveen las propiedades globales. Estas relaciones determinan las propiedades de las unidades segregadas. Y es posible llamar determinante a toda unidad que confiera una propiedad a otra unidad de un rango superior. Ejemplo: una boca puede ser identificada porque tiene la forma de boca (forma =determinante intrínseco que provee una unidad global) o porque está situada en el lugar de la boca dentro de la unidad superior cara.

Una unidad puede ser identificada por lo que es y por lo que no es. Eso se exalta en los enunciados retóricos, poéticos o enunciados que asocian varios significados a un mismo significante. Tal es el caso de algunos fotomontajes, cuyo nivel de redundancia es reducido, ya que al mismo tiempo que brindan 
asociaciones forzadas, ofrecen una fusión semántica, un tercer significado, de carácter retórico o poético. En el ejemplo el fotomontaje de un rostro, realizado mediante fotografías de ojos, boca, nariz, frente, cabello de diversas personas, de diverso tipo racial, sexo y cultura, representa y expresa «la mezcla, fusión, unidad e igualdad entre procedencias étnicas y sexos» (ver la figura de la página siguiente).

En el fotomontaje Rostro, encontramos todos los tipos de relaciones entre unidades estructurales (de coordinación, supraordenación y preordenación) que pueden establecerse mediante las relaciones de identidad, similitud, diferencia u oposición, y que dan lugar a la creación de figuras retóricas, puestas en soporte mediante operaciones de adjunción-supresión.

Asimismo, todas estas relaciones expuestas en el esquema de Palmer, pueden realizarse bien mediante las restantes operaciones de construcción poética (selección y articulación) y que en el marco de la construcción retórica son por: sustitución, (adjunción-supresión), adjunción, supresión, e intercambio o permutación de unidades visuales estructurales.

Finalmente, anotamos cinco formas de reconocer una unidad visual:

1. Por caracteres globales, es decir, por su contorno, su coloración media, su textura.

2. Por las relaciones posicionales que guarda con las unidades del mismo nivel jerárquico.

3. Por sus relaciones posicionales con la unidad que las engloba (unidad estructural superior).

4. Por sus relaciones con unidades en las que se descompone (y que por lo tanto, engloba: por ejemplo, un ojo fragmentado en pupila, pestañas, párpado, etc.).

5. Por las unidades que la han precedido en el tiempo y/o en la misma porción de espacio (imágenes en secuencia: sincrónica - momento estático en el tiempo, en un momento dado-o diacrónica —evolución en el tiempo)—(Grupo $\mu, 1987: 94)$.

Hemos visto el modelo de aplicación de avances semióticos en el proceso del diseño gráfico que se ha utilizado en la construcción del rostro. Se realizan las formas de reconocimiento de unidades semánticas estructurales de tipo visual. Se ha realizado el proceso creativo desde la selección y articulación de unidades sémicas de tipo visual, desde un universo de imágenes, la 


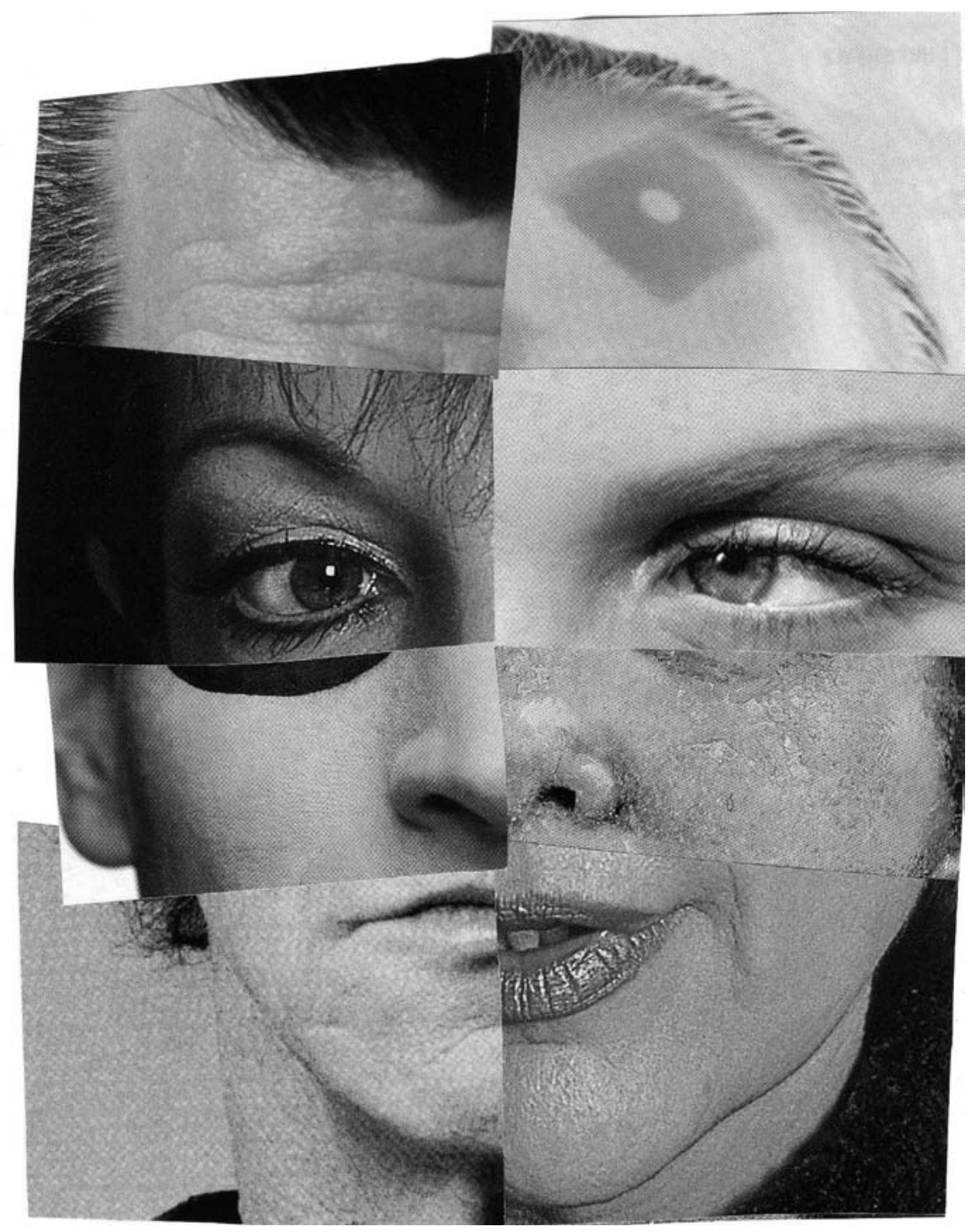

aplicación de una técnica (el fotocollage) y el montaje de unidades semejantes mediante operaciones de adjunción-supresión, para dar lugar a una alusión sobre la integración humana, mediante la visualización de sus diferencias y semejanzas. Igualmente se ha aplicado el esquema analítico de Palmer para construir el análisis estructural del proceso de creación e interpretación. 


\section{REFERENCIAS BIBLIOGRÁFICAS}

Abbagnano, N. (1986). Diccionario de filosofía. México: FCE.

BAÑuelos, J. (1995). Fotomontaje: síntesis visual. Madrid: Universidad Complutense.

Eco, U. (1988). De los espejos y otros ensayos. Barcelona: Lumen.

DuRAND, J. (1972). «Retórica e imagen publicitaria». En AA VV. Análisis de las imágenes. Buenos Aires: Tiempo Contemporáneo.

GreIMAS, A. J. y CourTÉs, J. (1982). Semiótica: diccionario razonado de la teoría del lenguaje. Madrid: Gredos.

GRUPO $\mu$ (1987). Retórica general. Barcelona: Paidós.

- (1992). Tratado del signo visual. Madrid: Cátedra.

JAKOBSON, R. (1981). «Lingüística y poética». En Ensayos de lingüística general. Barcelona: Seix Barral.

Peirce, Ch. S. (1932). Collected Papers, Cambridge, 1932. Cita tomada del libro de Ducrot, Oswald; Todorov, Tzvetan (1974). Diccionario enciclopédico de las ciencias del lenguaje. México: S. XXI Editorial.

SAussure, F. (1945). Curso de lingüística general. Buenos Aires: Losada. Cita tomada del libro de Ducrot, Oswald; Todorov, Tzvetan (1974). Diccionario enciclopédico de las ciencias del lenguaje. México: S. XXI Ed.

Todorov, Tzvetan (1974). Diccionario enciclopédico de las ciencias del lenguaje. México: Siglo XXI Ed.

ZunZunegui, S. (1989). Pensar la imagen. Madrid: Cátedra.

Zimmermann, Y. (1988). Del diseño. Barcelona: Gustavo Gili.

NOTA: Vjutemas Anagrama de los Estudios Superiores Estatales TécnicoArtísticos, instituidos por el gobierno soviético en Moscú (1920) y en Petrogrado y Vitebsk (1921); eran organismos autónomos y fueron importantes centros más o menos abiertos y experimentales de enseñanza, de desarrollo teórico y de discusión, en los que actuaron Malévich, Kandinsky, A. Pevsner y Tatlin. El centro V. de Moscú, en realidad, era (rebautizado) el antiguo Instituto de Pintura, Escultura y Arquitectura; estaba subvencionado por los Sindicatos se- 
miautónomos, y no directamente por el Estado. Otras instituciones que fomentaron el arte experimental fueron: el Injuk (Instituto de Cultura Pictórica), fundado en Moscú en 1920, y dirigido inicialmente por Kandisky; los Svomas (Estudios Libres de Arte), que sustituyeron por breve tiempo en Petrogrado a la Academia de Artes (restaurada en 1920); y el movimiento (Cultura Proletaria). Con la formación de la AJRR (Asociación de Artistas de la Rusia Revolucionaria) en 1922, decayó la tolerancia hacia la vanguardia. El llamamiento antiartístico de los constructivistas vinculados al periódico $L E F$ (Frente Izquierdistas de las Artes) lo orientó todo hacia 1922-24 al diseño industrial. 